\title{
Breve estudo sobre o Пovimento do Contestado: A historiografia militar e o caso dos operários da EFSPRG
}

Márcia Janete Espig*

\begin{abstract}
Resumo. O artigo a seguir elabora uma discussão historiográfica em torno do problema da presença de ex-operários da construção da Estrada de Ferro São Paulo - Rio Grande (EFSPRG) no movimento social do Contestado (1912-1916). Embora quase toda a historiografia afirme que eles tiveram participação destacada no conflito, constatei em minhas pesquisas que a única fonte documental mencionada é o Relatório do General Setembrino de Carvalho ao Ministro da Guerra, datado de 1916. A partir de um levantamento minucioso das demais obras produzidas por militares que participaram das forças repressivas, busco analisar qual a posição destes em relação à presença de ex-trabalhadores da Estrada de Ferro no movimento. Palavras-chave: Discussão historiográfica. Movimento do Contestado. EFSPRG.
\end{abstract}

O General Fernando Setembrino de Carvalho foi um militar dedicado à República. ${ }^{1}$ Durante sua existência, contribuiu para a manutenção do status quo republicano em diferentes locais da federação. Foi interventor no Ceará, por ocasião da crise política entre as elites locais, na qual esteve envolvida também a personalidade carismática de Padre Cícero (março a junho de 1914). Em seguida foi enviado, em setembro de 1914, à região do Contestado entre Paraná e Santa Catarina, onde permaneceu até maio do ano seguinte, cumprindo a difícil tarefa de pacificação. Passou por vários altos cargos militares 
Breve Estudo sobre o Movimento do Contestado...

e contribuiu para a repressão ao movimento tenentista (1922), sendo em seguida designado pelo presidente Artur Bernardes para o cargo de Ministro da Guerra (novembro de 1922), função que exerceu até o final daquele mandato (novembro de 1926). Nesta posição, coube-lhe a função de intervir na disputa intra-elites do Rio Grande do Sul, em 1923, sendo o negociador do Pacto de Pedras Altas (dezembro de 1923), entre a situação e a oposição gaúchas (Dicionário..., 2001, p. $1187-1190)^{2}$

Dentre tantas funções e tarefas, interessa-me analisar alguns aspectos de sua atuação durante a Campanha do Contestado, ${ }^{3}$ em que desempenhou a função de comandante das forças legais. ${ }^{4}$ Ao assumir, o movimento estava em sua fase de ascensão máxima, ocupando uma ampla zona e congregando um grande número de participantes. Segundo afirma um importante autor, naquele momento os rebeldes controlavam uma área de cerca de 28.000 quilômetros quadrados, chegando a somar aproximadamente 20.000 pessoas (Queiroz, 1966, p. 199). O General propôs, então, um plano de "estrangulamento" do movimento através de quatro colunas (Norte, Sul, Leste e Oeste) que progressivamente inviabilizariam o abastecimento dos rebeldes, concentrando-os em uma região central na qual se lhes prestou combate.

Um problema, entretanto, é definir a quem se combatia. Genericamente, os denominei "rebeldes", mas deve-se observar que formavam um grupo bastante heterogêneo. Sertanejos e caboclos que habitavam tradicionalmente a região, imigrantes chegados há pouco; migrantes de zonas próximas, bandidos que buscavam guarida na região pouco policiada: estes são alguns dos grupos mencionados pela historiografia que, no entanto, ainda não dedicou um estudo específico a esse tema. Um grupo teria chamado a atenção do General Setembrino: os ex-operários que construíram a ferrovia que atravessa a região contestada, a EFSPRG (Estrada de Ferro São Paulo - Rio Grande). Estes mereceram inclusive uma menção especial em seu Relatório apresentado ao General de Divisão José Caetano de Faria, Ministro da Guerra (1916). Segundo ele, 
Márcia Janete Espig

[...] com a construcção da São Paulo - Rio Grande, dada a especie dos operarios empregados nos serviços da linha, os sertões foram se enchendo dos peiores malfeitores, oriundos de todos os logares, principalmente de Pernambuco e do Rio. Terminada a construcção e por uma deslealdade dos empreiteiros commummente praticada com esses homens desprotegidos, foram os trabalhadores da linha abandonados nos mesmos sitios em que se achavam as turmas, a que pertenciam. Ora, esta gente, entre a qual se contavam celebres fascinoras, apurava, pela propria feição da sociedade em que viviam, de todo em todo fóra do influxo das leis, os attributos da coragem e da força, manejando por igual a picareta e a faca. $\mathrm{O}$ assassinio tornou-se, entre elles, um meio facil de resolver as minimas pendencias. Taes violencias, porém, nem sempre se limitavam á solução de uma duvida entre dois sujeitos. Algumas vezes, como pretexto á falta de pagamentos, ou como reacção aos desmandos dos feitores, houve levantes que exigiram a presença da força publica para apasigual-os. Era a escola em que se exercitavam futuros cabeças de acontecimentos mais graves (Carvalho, 1916, p. $3-4)$.

Esse pequeno trecho tornou-se muito importante para a historiografia sobre o Movimento do Contestado. Quase todas as obras escritas sobre o tema, seja por pesquisadores diletantes ou acadêmicos, vieram a incorporar a fala do General como indiscutível fonte de informação. $\mathrm{O}$ conhecimento daí advindo extrapolou inclusive o universo historiográfico, passando a compor um saber mais amplo, expresso pelos manuais de ensino de história. Neles, a vinda de um grupo de pessoas alheio à região do Contestado tornou-se um aspecto dado como consensual e que gerou uma linha de explicação para o movimento, ao propor como uma de suas causas essa presença. Embora essa seja uma informação trazida por praticamente todas as obras referentes a esse tema, a origem citada sempre será a mesma: o Relatório escrito pelo General Setembrino de Carvalho, não se mencionando, para tanto, outras fontes.

Anos 90, Porto Alegre, v. 14, n. 25, p.199-219, jul. 2007 
Breve Estudo sobre o Movimento do Contestado...

Todavia, até aqui essas afirmações não foram objeto de estudos acadêmicos detalhados. A fala do General adquiriu poder simbólico: um poder de world making - construção do mundo. Com base em um capital simbólico precedente, adquirido em lutas sociais anteriores (Bourdieu, 1990, p. 165-166), um enunciante passa a determinar o mundo, dizer como ele é (ou deve ser). Nas lutas simbólicas está em jogo o poder de produzir e impor a visão de mundo legítima em uma sociedade, ou seja, fazer crer. Como afirma Bourdieu: "O poder simbólico é um poder de fazer coisas com palavras" (p. 167). E a obra de Setembrino de Carvalho impôs uma visão sobre o Contestado que se tornou corrente, aceita e repetida por quase todos os estudos sobre esse movimento social. Essa versão afirma que os trabalhadores responsáveis pela construção da EFSPRG no trecho referente à zona contestada entre Paraná e Santa Catarina eram malfeitores, trazidos de grandes centros do país e abandonados na região ao final dos trabalhos. Ali teriam permanecido, tornando-se líderes da revolta posteriormente ocorrida. ${ }^{5}$

Neste artigo será meu objetivo estabelecer uma interpretação hermenêutica frente a esse pequeno trecho produzido pelo General Setembrino de Carvalho, relacionando-o a outros textos produzidos por militares que vivenciaram o conflito. Tal recorte privilegia apenas esse tipo de documentação, não sendo possível (por motivos de espaço) realizar aqui uma discussão mais ampla em relação a outros tipos de fontes. Pretendo demonstrar que a análise elaborada por Setembrino não será subscrita por outros memorialistas militares. Cabe, portanto, um questionamento à fala do General, por atingir a centralidade dessa temática. ${ }^{6}$

É provável que a diferença hierárquica, peça importante deste campo simbólico, tenha contribuído para a valorização inequívoca do texto do General sobre os demais textos produzidos por oficiais. Não se pode negar que a patente de General tem impressionado os leitores e estudiosos, que erroneamente são levados a supor um conhecimento superior ao de seus comandados. Quase todos os 
demais autores analisados, como veremos, pertenciam aos chamados quadros médios do Exército, especialmente tenentes e capitães. Estes quadros foram muito importantes no episódio. Um destes autores, Demerval Peixoto, considerava que a Campanha do Contestado poderia ser cognominada "dos tenentes", pois sobre os oficiais subalternos pesaram as tarefas mais difíceis. "Aos humildes nos galões coube a tarefa mais árdua desta peleja inglória" (1995c, p. 124). ${ }^{7}$

O Relatório do General Setembrino, publicado em 1916, tornouse imediatamente peça fundamental para o conhecimento do Contestado, e assim permanece. Incorporando uma série de documentos militares e de relatos sobre os enfrentamentos, proporciona informações de ordem militar, social e cultural. A dimensão assumida pelo Relatório qualifica-o como um monumento, no sentido expresso por Jacques Le Goff (1996). ${ }^{8}$ Esse documento/monumento - mentira e verdade ao mesmo tempo, montado e preservado por interesses variados - deve ser desmistificado, interrogado e visto como produto, de uma época, de um indivíduo, de um grupo. Acrescente-se a isso as considerações de Carlo Ginzburg sobre as relações de força envolvidas na constituição de uma documentação:

[...] ao avaliar as provas, os historiadores deveriam recordar que todo ponto de vista sobre a realidade, além de ser intrinsecamente seletivo e parcial, depende das relações de força que condicionam, por meio da possibilidade de acesso à documentação, a imagem total que uma sociedade deixa de si. Para "escovar a história ao contrário" [...] como Walter Benjamim exortava a fazer, é preciso ler os testemunhos às avessas, contra as intenções de quem os produziu. Só dessa maneira será possível levar em conta tanto as relações de força quanto aquilo que é irredutível a elas. (2002, p. 43).

Essa "leitura às avessas" contribui para uma nova visão do documento, que passa a ter sua compreensão obrigatoriamente 
Breve Estudo sobre o Movimento do Contestado...

associada a uma análise sofisticada. Mais do que um problema micro-histórico acerca de um assunto específico da história do Brasil, teremos como pano de fundo uma questão teóricometodológica fundamental, que é explicar a conformação de uma "verdade historiográfica" baseada em uma fonte documental apenas. Trata-se de um problema muito importante para os estudos sobre o Contestado, até aqui não analisado devido às dificuldades de localização da documentação pertinente e/ou desinteresse pelo tema.

\section{A historiografia militar sobre o Contestado: outros monumentos}

Muitos foram os militares, sobretudo oficiais, que combateram durante a Campanha do Contestado e nos legaram relatos escritos sobre essa experiência. Tais publicações iniciaram-se logo após o término do evento. O Relatório do General Setembrino (1916) será a primeira delas, e, como veremos, irá influenciar as demais. Essa primeira obra vinha apresentar ao Ministro da Guerra, o General José Caetano de Faria, os detalhes sobre a repressão e a resistência dos rebeldes, incluindo para tanto um grande volume de informações acerca do Movimento, a organização do Exército, o grande esforço empreendido etc. Já as publicações militares posteriores começaram a vir a público no mesmo ano, 1916, estendendo-se até os anos 70, possuindo um tom memorialístico e informativo. Em sua grande maioria, apresentam a ação do Exército no Contestado, tecendo considerações sobre os problemas então enfrentados. Rogério Rosa Rodrigues demonstra que, no momento da Campanha do Contestado, o Exército Nacional encontrava-se em um processo de reforma que buscava modernizá-lo e construir uma imagem do militar como cidadão. Concomitante a isso, um discurso de moralização e disciplinarização se fazia sentir através de idéias como progresso, patriotismo, nacionalismo (Rodrigues, 2001, p. 23). Sua missão seria, portanto, transcendente 
à função de defesa e segurança (p. 25). Nesse sentido, os memorialistas atribuíam-se uma função cívica, mais ou menos crítica, ao explicitar algumas das mazelas sociais que cumpria eliminar.

Acredito que um outro fenômeno, de ordem intelectual e editorial, tenha contribuído para essa profusão de publicações. A obra Os Sertões, de Euclides da Cunha, e sua reflexão sobre uma campanha anterior, porém ainda muito viva na consciência nacional, exerceu uma poderosa influência sobre esses oficiais. Parece-me que alguns (possivelmente a maioria) desejavam uma imortalização semelhante à daquele escritor, algo que não foi logrado por nenhum deles. ${ }^{9}$ Tal intenção pode ser constatada através do formato de alguns dos livros e dos recursos literários utilizados (Rodrigues, 2001, p. $35-38) \cdot{ }^{10}$

Selecionei as obras de alguns autores militares para cumprir os objetivos deste artigo. Eles apresentam as memórias mais citadas e utilizadas pela historiografia. São eles: $2^{\circ}$ Tenente Demerval Peixoto, que publica sob o pseudônimo de Clivelaro Marcial uma obra em três partes intitulada Campanha do Contestado (1995a, 1995b, 1995c); ; $1^{\circ}$ Tenente Herculano d'Assumpção, que publica o primeiro volume de seu trabalho em 1917 e o segundo volume em 1918; $2^{\circ}$ Tenente J. O. Pinto Soares, que será um autor prolífero, tendo produzido vários livros sobre o tema (1920, 1931, s/d); oficiais médicos Ezequiel Antunes (1918) e Alves Cerqueira (1936); capitão Vieira da Rosa, cuja narrativa jamais foi publicada, permanecendo datilografada junto ao acervo do Instituto Histórico e Geográfico de Santa Catarina.

Essas obras representam uma primeira geração da historiografia sobre o Contestado. ${ }^{12}$ Vão além, porém, pois são relatos de participantes diretos do conflito. Mais do que isso: são monumentos, no sentido discutido acima, utilizados desde seus primórdios como base para informação sobre o Contestado. As gerações seguintes de historiadores não deixaram de utilizá-las, muito embora tenha variado bastante o uso e o sentido conferido a tais relatos. Se alguns analistas as utilizaram 
Breve Estudo sobre o Movimento do Contestado...

acriticamente, como mera fonte de dados "objetivos" sobre o conflito, atualmente a tendência aponta para uma análise mais refinada dessas fontes. Tenta-se desvendar os determinantes que agiram sobre os autores, examinando sua cultura ou mesmo seu preconceito, filtros que, em alguns momentos, levarão inclusive a distorções na informação. Entretanto, mesmo a sugestão de superioridade cultural conduz os textos, em alguns casos, a uma descrição quase antropológica dos fenômenos (Espig, 2002, p. 76-77). Temos, portanto, uma riqueza considerável, que exigirá uma leitura atenta, teórica e metodologicamente orientada.

A fim de investigar o problema que venho propondo, deverei cotejar esses monumentos àquele já destacado acima, o Relatório do General Setembrino. Meu objetivo será observar se tais obras referem-se ou não à existência, dentre os rebeldes, de ex-operários da EFSPRG, e demais informações que possam ser alcançadas sobre esse tópico. Nesse sentido, busco saber se os militares que escrevem após Setembrino corroboram sua informação ou se a abandonam.

O conteúdo do Relatório merece alguns comentários. Parte das notícias trazidas por Setembrino não são exatas, e foram reelaboradas por relatos posteriores ou rebatidas pela historiografia. Posso apontar, como exemplo, a identificação de Francisco Paes de Farias ao codinome de Venuto Baiano. Na verdade, trata-se de indivíduos distintos. Francisco Paes de Farias era Chico Ventura, um dos responsáveis pelo início dos ajuntamentos; Venuto Baiano era uma das lideranças de guerra, importante na fase dos combates (Carvalho, 1916, p. 13). ${ }^{13}$ Outra informação imprecisa prestada pelo General atribui a Praxedes Gomes o título de "chefe dos rebeldes", quando se sabe que este fazia comércio com o grupo, mas não se envolveu ativamente em sua organização (Carvalho, 1916, p. 9). Uma ausência sentida no Relatório refere-se a Adeodato Ramos, famoso líder da fase final do Movimento, e que não mereceu qualquer comentário por parte do autor. 
Esses exemplos não desqualificam tal documentação, mas nos direcionam para duas importantes constatações. Primeiramente, observamos que a rapidez imposta ao General para a elaboração de seu Relatório pode ter levado a algumas afirmações frágeis, visto que o objetivo principal de seu texto não era uma narrativa histórica sobre o evento, mas um relato da atividade do Exército Nacional. Devemos ainda observar, como um segundo aspecto importante, o fato de que os militares eram estranhos à região, ou seja, seu conhecimento sobre a população sertaneja era certamente menor do que poderíamos ser levados a supor. ${ }^{14} \mathrm{O}$ General Setembrino baseou-se, ao escrever seu Relatório, em partes de combate, inquéritos e demais documentos produzidos na frente de batalha por seus oficiais. Embora o próprio General conteste a afirmação segundo a qual teria dirigido as operações à distância, instalado no Quartel-General em Curitiba, conforme propalado na época pelos jornais, o fato é que a expedição Setembrino durou apenas alguns meses - tempo insuficiente para um bom conhecimento da cultura local. O próprio convívio entre praças e sertanejos foi proibido pelo General, a fim de diminuir a prática de espionagem (Carvalho, 1916, p. 47).

As publicações posteriores contarão com o benefício da prévia existência dessa obra paradigmática (embora, como já destaquei, contassem ainda com a influência onipresente de Euclides da Cunha). Alguns de seus autores escreveram artigos publicados em vários jornais do país, como d'Assumpção, Vieira da Rosa e Pinto Soares. Isto nos ajuda a entender a existência de uma certa sintonia analítica entre essas fontes e os argumentos expressos pelos jornais da época, sobretudo os referentes à "ausência de cultura", "ignorância", "inferioridade", etc., aspecto ainda não suficientemente explorado pela historiografia. ${ }^{15}$

Lendo-se atentamente, pode-se constatar em alguns casos, e inferir em outros, o conhecimento mútuo entre os autores citados acima. Sobretudo o Relatório, devido à sua condição de autoridade 
Breve Estudo sobre o Movimento do Contestado...

e precedência temporal, era conhecido pelos demais autores, sendo diretamente citado em inúmeras ocasiões, e indiretamente utilizado em outras. D'Assumpção o utiliza com freqüência, e em alguns momentos a intertextualidade torna-se explícita:

Não resisto ao desejo de transcrever aqui, com a devida venia, uma pagina do relatorio do general Setembrino, na qual nitidamente está descripto o admiravel feito do pequeno grupo de vaqueanos bravamente dirigido pelo Joaquim Gonçalves [...]. (d'Assumpção, 1918, p. 30).

Além do próprio Relatório, os autores citam-se abundantemente entre si. Destacarei exemplos a fim de fornecer subsídios para algumas argumentações que irei realizar mais adiante. D’Assumpção credita, em nota de rodapé, determinada informação como "[...] acceita pelo distincto colega que se occulta sob o pseudonymo de 'Crivelaro Marcial"' (1917, p. 216). Mais adiante, transcreve um bilhete, destacando que já havia sido publicado por Crivelaro Marcial (p. 246). ${ }^{16}$ D'Assumpção transcreve ainda um longo trecho de Cerqueira (p. 255-258).

Muito provavelmente o General Setembrino de Carvalho elaborou a leitura das obras seguintes à sua. Pelo menos uma dessas foi citada em suas Memórias, quando se refere ao livro de Demerval Peixoto como um "repositório apreciável de detalhes" sobre a Campanha (Carvalho, 1950, p. 172). As demais não chegaram a merecer seus comentários.

\section{A historiografia militar e os trabalhadores da EFSPRG}

A fim de esclarecermos a posição dos autores mencionados acima sobre os operários da Estrada de Ferro, devemos observar sua visão sobre os participantes do Movimento em geral. Sua interpretação partilha de um olhar etnocêntrico e preconceituoso, através 
do qual se reconhecem características de inferioridade nas populações sertanejas. Os participantes do Movimento do Contestado serão avaliados e sentenciados através de categorias estranhas à sua cultura. A maioria dos intelectuais que os descreveram em sua contemporaneidade, via de regra figuras urbanas e alheias à cultura cabocla, trabalharam no sentido de apontar as diferenças entre si e os "fanáticos", chocados pela violência dos conflitos. Invariavelmente, observamos denominações pejorativas para esses agentes, tais como "bandidos", "bandoleiros", "ignorantes", entre muitos outros qualificativos depreciativos.

Uma variante foram as avaliações paternalistas, que destacam o fato de que aqueles "pobres patrícios" não teriam recebido do Estado ou da sociedade condições honrosas de vida, sobrevivendo em uma estupidez e ignorância pela qual não seriam os únicos culpados. Fortemente presente em algumas fontes jornalísticas, essa representação surge também nos relatos militares, podendo desembocar ou não em uma apreciação crítica sobre os poderes públicos. O Tenente J. O. Pinto Soares, por exemplo, afirma: “Com effeito, as luctas do Contestado, á luz serena dos factos, tiveram sua origem no fanatismo, que por sua vez germinou da falta de instrucção popular e de policiamento regular [...]" (1920, p. 110).

Dentre os militares consultados, é possível observar uma recorrente referência a participantes da Revolução Federalista ou a outros elementos, considerados como "bandidos", que teriam se instalado na região e dirigido os rebeldes em suas ações.

Pinto Soares destaca que:

A região inhospita éra habitada, em grande parte, por individuos criminosos e foragidos á acção da lei penal, do Rio Grande do Sul, Paraná e Santa Catharina, formando uma população perigosa (Soares, 1920, p. 07).

Em outro momento, o mesmo autor faz-se mais preciso: "No Contestado, porém, o inimigo era um mixto de fanaticos, bandidos 
Breve Estudo sobre o Movimento do Contestado...

e exploradores de todos os matizes". E complementa, em nota de rodapé:

Com a locomoção facilitada pela via-ferrea S.P.-R.G., a fertilissima região inculta viu-se infestada tambem por individuos perniciosos provindos do Norte do Paiz, inclusive muitos dos marinheiros sediciosos de 1910, e desertores do Exercito e da Policia (Soares, s/d, p. 127).

Peixoto considera que os pobres "fanáticos", "ignorantes", foram na verdade manipulados pelos "bandidos" e "aventureiros" (1995a, p. 52), cuja proveniência era ampla:

Ponto de atração de criminosos e desocupados de diversos estados brasileiros, como de certa zona da Argentina e do Paraguai, aquele cenário de crendice religiosa cresceu e apareceu como coisa tenebrosa, expandindo malefícios dentro de um círculo de ação que, por fim, abrangia toda circunscrição territorial do interior catarinense e grande trecho do Contestado (Peixoto, 1995a, p. 59-60).

Acredito que a avaliação segundo a qual os líderes mais perigosos do movimento seriam de fora da região mostra uma tendência de análise por parte dos militares. Essa explicação tenta resolver um dilema central: como justificar que um grupo de sertanejos "ignorantes" tenha conseguido se organizar a ponto de resistir a vários ataques das forças legais, dominando uma grande parcela do território Contestado. Para os oficiais que nos legaram seus escritos, a população local era incapaz de resistir ao Exército Nacional. ${ }^{17}$ Os sertanejos eram vistos como um grupo intelectualmente incapaz de se autodirigir na situação de conflito; para cumprir tal tarefa, deveria haver bandidos contumazes dos Estados e regiões vizinhas, alguns inclusive antigos participantes da Revolução Federalista, tornando as derrotas iniciais do Exército frente aos rebeldes algo aceitável. 
Uma variante sobre esse predomínio de lideranças externas à região é a versão apontada pelo Relatório do General Setembrino, como já destacado acima. Nesta versão, o papel de liderança será assumido pelos operários da construção da EFSPRG, cuja condição social desclassificada presumia os atos criminosos que se seguiram. Pode-se observar uma forte tendência em se relacionar a liderança do movimento a personagens advindas de outros contextos. Ao sertanejo, autóctone, simplório, cabe apenas o papel de soldado, jamais de general.

Chegamos ao momento do texto em que devo forçosamente responder a um problema fundamental: como os autores militares que publicam após o Relatório do General se referem aos operários da EFSPRG, sua vinda para a região, sua composição social?

Surpreendentemente, eles não falam sobre o assunto. Nenbum deles subscreve ou mesmo comenta a vinda de operários de outras regiões para o Contestado. Como já mencionei, os escritores analisados acreditavam que a zona era um local perigoso, onde se encontravam foragidos da polícia e bandidos diversos, parte deles ligada à Revolução Federalista; entretanto, não encontramos em suas obras referências à migração que Setembrino de Carvalho afirma de forma tão categórica. Todavia, se não reproduzem, os autores também não desmentem ou contestam esse dado, simplesmente não o comentando. Teria o peso simbólico da figura do General anulado possíveis discordâncias? Conforme veremos mais abaixo, apenas um dos militares analisados nos trará uma informação sobre esses operários. Esta, porém, será distinta daquela prestada por Setembrino.

Se as fontes não nos respondem diretamente à indagação, podemos seguir para uma interpretação mais elaborada metodologicamente. Com isso, quero sugerir que essa documentação deva sofrer uma leitura a contrapelo, ou o que o historiador inglês E. P. Thompson denomina "leitura infernal" (Thompson, 1981, p. 36). Isso pode ser elaborado através de uma análise minuciosa que tente 
Breve Estudo sobre o Movimento do Contestado...

observar, entre o dito e o não-dito, onde poderia se situar a informação sobre a composição social do Movimento do Contestado, observando a presença de personagens alheios à região. Como afirma Ginzburg:

A idéia de que as fontes, se dignas de fé, oferecem um acesso imediato à realidade, me parece [...] rudimentar. As fontes não são nem janelas escancaradas, como acreditam os positivistas, nem muros que obstruem a visão, como pensam os cépticos: no máximo poderíamos compará-las a espelhos deformantes. (Ginzburg, 2002, p. 44).

Dessa maneira, cabe ao historiador explicar, construir, analisar a documentação, desvendando seu aspecto "deformante" e explicitando aquilo que seu autor não quis ou não pôde mencionar.

Assim, posso destacar nas obras em questão um hiato. Este hiato dá-se entre a representação que afirma a presença de "bandidos forasteiros" e a descrição, objetivamente elaborada, de indivíduos capturados pelas forças. Os rebeldes aprisionados e descritos ao longo das narrativas serão, em todas as ocasiōes, sertanejos naturais da região. Citarei sobre esse assunto alguns exemplos. D'Assumpção, ao longo de suas 840 páginas, descreve muitos "fanáticos" ou bandoleiros que foram feitos prisioneiros. Nesse sentido, fará uma série de relatos interessantes, tecendo inclusive comentários morais e de ordem racial. As descrições feitas sobre os prisioneiros, no entanto, sempre destacam o fato de serem moradores da região. Este é o caso do prisioneiro Maurílio Gomes, descrito como "sertanejo bronco e analphabeto" (d’Assumpção, 1917, p. 80); ou então o facínora Manoel Lourenço de Andrade, qualificado como "[...] um caboclo ainda moço, mas de um aspecto repellente" (d'Assumpção, 1918, p. 237). Esse formato de descrições prepondera também nos relatos dos demais militares citados. Pinto Soares, por exemplo, também registra a prisão do jagunço Manoel Lourenço de Andrade, nascido e criado em Curitibanos (s/d, p. 75; 1931, p. 124). Através da transcrição de uma notícia do 
jornal O Estado, de Florianópolis, o mesmo autor comenta a prisão de Cyrino Pedro de Oliveira, vulgo Cyrino Chato, descrito como "[...] um caboclo baixo, moreno, de rosto oval [...]", natural de Curitibanos (Soares, 1920, p. 87). Seu companheiro, aprisionado na mesma ocasião, era Salvador Ferreira Nunes, natural do Paraná e também qualificado como caboclo (Soares, 1920, p. 88). Poucos prisioneiros não terão sua procedência detalhada, como é o caso do indivíduo José Baptista, apenas identificado como "morador nas Perdizinhas" (Soares, s/d, p. 78). Formato parecido também está presente em autores como Peixoto e Vieira da Rosa. O próprio Setembrino de Carvalho, ao publicar suas Memórias décadas após a campanha, destaca seu combate contra os "fanáticos", populações de sertanejos ignorantes, "segregados dos centros de civilização, obedecendo quase somente aos impulsos naturais", sem especificar os ex-operários como possíveis componentes do grupo (Carvalho, 1950, p. 134).

Também é freqüente a denominação dos rebeldes como "bandidos" ou "bandoleiros", muito mais genérica e que poderia expressar não apenas a idéia de combatentes locais. Entretanto, constata-se que os fugitivos, bandidos ou operários, descritos em geral mais ao início dos relatos em questão, não surgem posteriormente na narrativa do conflito. Destacados como "cabecilhas" ou grandes instigadores do movimento, esses agentes desaparecem no transcorrer do Relatório do General Setembrino e também nas obras dos autores que analisei. Ou seja, a afirmação de que sujeitos externos à região teriam contribuído para o desenvolvimento do movimento, que de início parece tratar-se de tópico bastante importante nas narrativas, não comparece no desenvolvimento dos textos como uma base analítica convincente. Permanece de forma manifesta o sentimento de diferença frente aos caboclos, aos sertanejos "transviados", ignorantes e manipuláveis.

Apenas Pinto Soares nos oferece alguma informação sobre a permanência dos ex-operários da EFSPRG na região do Contestado 
Breve Estudo sobre o Movimento do Contestado...

e sua adesão à revolta. Segundo o Tenente, muitos homens (cerca de mil) teriam sido dispensados em 1914 da construção do Ramal São Francisco, devido à paralisação dos trabalhos. Só então, e devido à falta de ocupação, a maioria teria aderido à "revolução" (Soares, 1920, p. 112). Cabe, porém, o destaque às diferenças. A versão de Pinto Soares, em certo sentido, questiona a representação segundo a qual os trabalhadores teriam assumido um papel de liderança no movimento, visto que teriam aderido apenas a partir de 1914. Além disso, afirma esse autor, dentre os trabalhadores estariam "estrangeiros e nacionais", e não apenas bandidos e facínoras provenientes dos grandes centros brasileiros, como destaca o General. ${ }^{18}$

\section{Conclusão}

A referência do General Setembrino aos trabalhadores da Estrada de Ferro, ao ser contrastada com variadas obras memorialísticas de militares que participaram da Campanha do Contestado, não recebeu confirmação. Conforme demonstrei acima, ao escrever suas obras os oficiais conheciam não apenas o texto do General Setembrino, mas também os livros precedentes de seus colegas e, em alguns casos, seus esboços e diários pessoais. Entretanto, essa intertextualidade não basta para que expliquemos a ausência de referências aos ex-operários da EFSPRG nos autores que escrevem posteriormente ao Relatorio, com exceção da já analisada menção feita pelo Tenente Pinto Soares. Os oficiais não confirmam ou desmentem diretamente a versão apresentada por Setembrino de Carvalho. É possível que a questão da hierarquia tenha influenciado nesse aspecto da narrativa. Ao não se referir a elementos de fora da região no momento em que descrevem os prisioneiros capturados, porém, tais obras nos sugerem e direcionam decididamente para um questionamento da informação prestada pelo General, reforçando a necessidade de uma investigação mais ampla que contraste suas afirmações com variada documentação de época. 


\section{Márcia Janete Espig}

\section{Brief study on Contestado Movement: military historiography and the case of EFSPRG's workers}

Abstract. The following article carries on a historical discussion about the problem of the presence of former workers in the building of São Paulo-Rio Grande Railway (EFSPRG) in Contestado Social Movement (1912-1916). Although almost the entire historiography confirms their participation in the conflict, I could prove through my research that the only document mentioned is Setembrino de Carvalho's Report to the War Minister, dated 1916. Through detailed research of other works by militaries involved in repression, I intend to analyze which were their positions concerning the presence of former workers in the Movement.

Keywords: Historical discussion. Contestado Movement. EFSPRG.

\section{Notas}

${ }^{1}$ Embora o posto mais alto alcançado por Setembrino de Carvalho na hierarquia militar tenha sido o de Marechal - superior, portanto, ao de General - irei referir-me a ele como General por dois motivos: primeiramente, este era o posto exercido ao dirigir a Campanha do Contestado; segundo, porque essa é a nomenclatura a ele atribuída por toda historiografia referente a esse tema.

2 Afastou-se da vida pública assim que saiu do Ministério da Guerra, tendo falecido em 1947. Em 1950 veio a público, postumamente, seu livro Memórias - dados para a bistória do Brasil, em que registrou e analisou as experiências proporcionadas por sua marcante atuação político-militar durante a República Velha.

${ }^{3}$ Utilizarei a nomenclatura "Campanha do Contestado" nos momentos em que fizer referência especificamente ao episódio militar e à experiência do Exército Nacional na região. A expressão "Movimento do Contestado", preferida por mim, é mais ampla e abrange todo o processo histórico em questão, sendo utilizada neste artigo para denotar as características sociais do mesmo.

${ }^{4}$ Ocorrido entre os anos de 1912 e 1916, o Contestado foi um movimento social de caráter messiânico e milenarista localizado no interior do território que corresponde atualmente ao meio-oeste catarinense. O nome "Contestado" é uma referência a dois antigos conflitos de limites: entre Argentina e Brasil (a Questão de Missiones, ou Palmas, solucionada pelo governo republicano em 1896) e, posteriormente, entre os Estados de Santa Catarina e Paraná. A disputa pela região criou um clima de tensão local, agravado pelas expulsões de terra devido à construção da EFSPRG. Sobre esse conflito, existe uma ampla e qualificada historiografia, como Vinhas de Queiroz (1966), Cabral (1979), Monteiro (1974), Auras (1995) e, mais recentemente, Machado (2004).

Anos 90, Porto Alegre, v. 14, n. 25, p.199-219, jul. 2007 
Breve Estudo sobre o Movimento do Contestado...

${ }^{5}$ Machado (2004), em sua tese de doutoramento, estudou as lideranças do Contestado. Demonstrou de forma inequívoca que entre estes personagens não se localizam exoperários da EFSPRG, refutando parte importante das afirmações do General.

${ }^{6}$ Essa reflexão é parte de um estudo maior, representado por minha tese de doutoramento, na qual discuto o problema dos trabalhadores da EFSPRG de forma mais ampla e recorrendo a um volume significativo de documentação. A tese encontra-se em fase final de redação.

${ }^{7}$ Somando a isso as constantes criticas à "politicagem", personificada nos chefes políticos e coronéis, poderíamos entender tais descontentamentos como uma semente precursora dos ideais do movimento tenentista vindouro. Se considerarmos que os objetivos do movimento tenentista da década de 1920 giravam em torno da reforma do Exército e da reforma social, já percebemos em germe ambas as críticas no texto dos tenentes e capitães que lutaram no Contestado e escreveram antes de 1922. Em seus textos, contudo, não se percebe ainda a quebra de hierarquia, pois as críticas diretas aos oficiais superiores são veladas ou matizadas. Sobre o movimento tenentista e a quebra de hierarquia, conferir, dentre outros, o artigo de Lanna (In Ferreira e Delgado, 2003), o estudo clássico de Fausto (1997), o trabalho de Borges (1992) e a obra de Sodré (1979).

8 "O documento não é inócuo. É, antes de mais nada, o resultado de uma montagem, consciente ou inconsciente, da história, da época, da sociedade que o produziram, mas também das épocas sucessivas durante as quais continuou a viver, talvez esquecido, durante as quais continuou a ser manipulado, ainda que pelo silêncio" (Le Goff, 1996, p. 547). E, mais adiante: “Todo documento é monumento. [...] No limite, não existe um documento-verdade” (p. 548).

${ }^{9}$ Essa intenção comparece abertamente no texto de alguns dos oficiais aqui analisados. Mesmo algumas obras historiográficas posteriores não escapam dessa influência, estabelecendo comparações e muitas vezes afirmando uma maior "grandiosidade" do Contestado em relação a Canudos.

${ }^{10}$ Liz Andréa Dalfré sublinha a centralidade do pensamento euclidiano na comunidade de imaginação que veio a formatar o discurso tanto dos militares quanto dos jornais do período (2004, p. 133-144).

${ }^{11}$ A primeira parte veio a público em 1916, a segunda, em 1918 e, no ano de 1920, uma edição conjunta reúne a publicação completa. Em 1995, foi produzida uma segunda edição, em três volumes separados, que pautou minha análise neste artigo. ${ }^{12}$ Existem ainda algumas obras de militares, mais recentes, cujos autores não tiveram participação direta na Campanha do Contestado. Estes recorrem a bibliografias e fontes (em geral militares), e via de regra seu objetivo é defender a memória da instituição, dos oficiais e soldados. Nesse sentido, desvalorizam o caráter social do movimento, tentando demonstrar que se tratou de banditismo, não restando ao Exército outra opção além de combatê-lo.

Anos 90, Porto Alegre, v. 14, n. 25, p.199-219, jul. 2007 
Márcia Janete Espig

${ }^{13}$ Essa informação errônea foi transcrita por d'Assumpção no volume 1 de sua obra (1917, p. 264), mas corrigida no volume 2 (1918, p. 18).

${ }^{14}$ Questão já apontada por Machado (2004, p. 146).

${ }^{15}$ Já a potencialidade de uso dos jornais como fonte para o Contestado foi objeto de alguns estudos, dentre os quais uma publicação de minha autoria (Espig, 1998). Sobre esse assunto, consultar ainda o segundo capítulo da dissertação de mestrado de Dalfré (2004), no qual a autora reflete sobre a imprensa paranaense, com destaque para o jornal Diário da Tarde, de Curitiba. Já a obra de Weinhardt (2000) elabora a análise de alguns discursos sobre o conflito, utilizando, dentre outras modalidades de discurso, o texto jornalístico do Diário da Tarde (p. 27-61).

${ }^{16}$ Não há dúvidas de que conhecia pessoalmente o $2^{\circ}$ Tenente Demerval Peixoto, pois descreve um episódio em que este foi alvejado por uma bala inimiga na mão esquerda (1918, p. 387).

${ }^{17}$ Opinião semelhante já foi expressa por Machado (2004, p. 145) ao referir-se à famosa citação do General Setembrino de Carvalho.

${ }^{18}$ Como bom leitor de Pinto Soares, Peixoto reproduz a informação de que os trabalhadores do ramal São Francisco foram às armas (1995b, p. 38), sem acrescentar, entretanto, informações adicionais sobre o assunto.

\section{Fontes Impressas}

ANTUNES, Ezequiel. O Contestado entre Paraná e Santa Catarina. Belém: Imprensa Oficial do Estado, 1918.

CARVALHO, Fernando Setembrino de. Relatório apresentado ao General de Divisão José Caetano de Faria, Ministro da Guerra. Rio de Janeiro: Imprensa Militar, 1916. Memórias - dados para a história do Brasil. Rio de Janeiro: s/ed, 1950.

CERQUEIRA, Alves. A jornada de Taquaruç (feito guerreiro). Contribuição ao estudo da história militar do Brasil. Rio de Janeiro: s/ed, 1936.

d'ASSUMPÇÃO, Herculano Teixeira. A campanha do Contestado (as operações da Columna do Sul). Belo Horizonte: Imprensa Oficial do Estado de Minas Gerais, 1917. v. 1.

A campanha do Contestado (as operações da Columna do Sul). Belo Horizonte: Imprensa Oficial do Estado de Minaes Gerais, 1918, v. 2.

PEIXOTO, Demerval (Clivelaro Marcial). Campanha do Contestado - Episódios e impressões. Rio de Janeiro: Segundo Milheiro, 1920.

Anos 90, Porto Alegre, v. 14, n. 25, p.199-219, jul. 2007 
Breve Estudo sobre o Movimento do Contestado...

PEIXOTO, Demerval. Campanha do Contestado. Curitiba: Fundação Cultural, 1995a. Campanha do Contestado. Curitiba: Fundação Cultural, 1995b. Campanha do Contestado. Curitiba: Fundação Cultural, 1995c.

ROSA, José Vieira da. A campanha do Contestado. Florianópolis: s/d, (dat.).

SOARES, J. O. Pinto. Subsidios para a história - o Contestado. Porto Alegre: Oficinas gráficas da Escola de Engenharia de Porto Alegre, 1920. v. I.

O Contestado. Subsídios para a história (1914-1915). Santa Maria: Papelaria Ângelus, s/d. v. II.

Guerra em Sertões Brasileiros. Rio de Janeiro: Papelaria Velho, 1931.

\section{Referências}

ABREU, Alzira Alves de. et al. Dicionário histórico-biográfico brasileiro pós-30. 2. ed. revista. Rio de Janeiro: Editora FGV/CPDOC, 2001.

AURAS, Marli. Guerra do Contestado: a organização da irmandade cabocla. 2. ed. Florianópolis : Editora da UFSC, 1995.

BORGES, Vavy Pacheco. Tenentismo e revolução brasileira. São Paulo: Brasiliense, 1992.

BOURDIEU, Pierre. Coisas ditas. São Paulo: Brasiliense, 1990.

CABRAL, Oswaldo Rodrigues. A Campanha do Contestado. 2. ed. Florianópolis: Editora Lunardelli, 1979.

DALFRÉ, Liz Andréa. Outras narrativas da nacionalidade: o movimento do Contestado. Dissertação (Mestrado em História) - Programa de Pós-Graduação em História Setor de Ciências Humanas, Letras e Artes, Universidade Federal do Paraná, Curitiba, 2004.

ESPIG, Márcia Janete. O uso da fonte jornalística no trabalho historiográfico: o caso do Contestado. Estudos Ibero-americanos, Porto Alegre, v. XXIV, n. 02, p. 269-289, 1998.

- A presença da gesta carolingia no movimento do Contestado. Canoas: Ed. da Ulbra, 2002.

FACHEL, José Fraga. Monge João Maria: recusa dos excluídos. Porto Alegre/ Florianópolis: Editora da UFGRS/UFSC, 1995.

Anos 90, Porto Alegre, v. 14, n. 25, p.199-219, jul. 2007 
Márcia Janete Espig

FAUSTO, Boris. História do Brasil. 6 ed. São Paulo: Ed. da USP, 1999.

FERREIRA, Jorge; DELGADO, Lucilia de Almeida Neves (org.). O Brasil Republicano: o tempo do liberalismo excludente - da Proclamação da República à Revolução de 1930. Rio de Janeiro: Civilização Brasileira, 2003.

GINZBURG, Carlo. Relações de força- história, retórica, prova. São Paulo: Companhia das Letras, 2002.

LE GOFF, Jacques. História e memória. 4. ed. Campinas: UNICAMP, 1996.

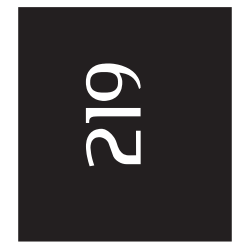

MACHADO, Paulo Pinheiro. Lideranças do Contestado: a formação e a atuação das chefias caboclas (1912-1916). Campinas: Ed. da UNICAMP, 2004.

MONTEIRO, Duglas Teixeira. Os errantes do novo século: um estudo sobre o surto milenarista do Contestado. São Paulo: Duas Cidades, 1974a.

PEREIRA DE QUEIROZ, Maria Isaura. La "Guerre Sainte” au Brésil: Le mouvement messianique du "Contestado". São Paulo: Faculdade de Filosofia, Ciências e Letras da Universidade de São Paulo, 1957.

O messianismo no Brasile no mundo. São Paulo: Alfa-Ômega, 1977.

QUEIROZ, Maurício Vinhas de. Messianismo e conflito social (a guerra sertaneja do Contestado - 1912-1916). Rio de Janeiro: Civilização Brasileira, 1966.

RODRIGUES, Rogério Rosa. Os sertões catarinenses: embates e conflitos envolvendo a atuação militar na Guerra do Contestado. Dissertação (Mestrado em História) Centro de Filosofia e Ciências Humanas, Universidade Federal de Santa Catarina, Florianópolis, 2001.

SODRÉ, Nelson Werneck. História militar do Brasil. 3. ed. Rio de Janeiro: Civilização Brasileira, 1979.

THOMPSON, E. P. A miséria da teoria ou um planetário de erros - uma crítica ao pensamento de Althusser. Rio de Janeiro: Zahar, 1981.

WEINHARDT, Marilene. Mesmos crimes, outros discursos? Algumas narrativas sobre o Contestado. Curitiba: Ed. da UFPR, 2000.

Recebido em 29/08/2006

Aprovado em 03/08/2007

Anos 90, Porto Alegre, v. 14, n. 25, p.199-219, jul. 2007 